\title{
BM] Global Health e-PC101: an electronic clinical decision support tool developed in South Africa for primary care in low-income and middle-income countries
}

\author{
Matthew Yau, ${ }^{\oplus 1}$ Venessa Timmerman, ${ }^{2}$ Merrick Zwarenstein, ${ }^{\oplus}$ Pat Mayers, ${ }^{2}$ \\ Ruth Vania Cornick, ${ }^{2}$ Eric Bateman, ${ }^{2,4}$ Lara Fairall ${ }^{2,4}$
}

To cite: Yau M, Timmerman V, Zwarenstein M, et al. e-PC101: an electronic clinical decision support tool developed in South Africa for primary care in lowincome and middle-income countries. BMJ Glob Health 2019:3:e001093. doi:10.1136/ bmjgh-2018-001093

Handling editor Seye Abimbola

- Additional material is published online only. To view please visit the journal online (http://dx.doi.org/10.1136/ bmjgh-2018-001093).

Received 3 August 2018 Revised 17 January 2019 Accepted 19 January 2019

Check for updates

(c) Author(s) (or their employer(s)) 2019. Re-use permitted under CC BY-NC. No commercial re-use. See rights and permissions. Published by BMJ.

${ }^{1}$ University of Toronto Medical School, Toronto, Ontario, Canada ${ }^{2}$ Knowledge Translation Unit, University of Cape Town Lung Institute, Cape Town, South Africa

${ }^{3}$ Centre for Studies in Family Medicine, Schulich School of Medicine \& Dentistry, Western University, London, Ontario, Canada

${ }^{4}$ Department of Medicine, University of Cape Town, Cape Town, South Africa

Correspondence to

Matthew Yau;

matt.yau@mail.utoronto.ca

\section{ABSTRACT}

Health technology is increasingly recognised as a feasible method of addressing health needs in low and middleincome countries (LMICs). Primary Care 101, now known as PACK (Practical Approach to Care Kit), is a printed, algorithmic, checklist-based, comprehensive clinical decision support tool. It assists clinicians with delivering evidence-based medicine for common primary care presentations and conditions. These assessment and treatment guides have been adopted widely in primary care clinics across South Africa. This paper focuses on the process of designing, developing, and implementing a digital version of the clinical decision support tool for use on a tablet computer. Lessons learnt throughout its development and pilot implementation could apply to the creation of electronic health interventions and the digitisation of clinical tools in LMICs.

\section{INTRODUCTION}

The field of electronic health (eHealth) is growing rapidly, especially in low and middle-income countries (LMICs). ${ }^{1}$ With technological advances becoming increasingly accessible across the world, health systems are turning to digitisation to improve efficiency and quality of care. ${ }^{2}$ The Knowledge Translation Unit (KTU) at the University of Cape Town has led the development and implementation of a digital clinical decision support tool. This tablet-based eHealth intervention was designed for use by clinicians caring for adult ambulatory patients in LMIC settings.

This paper provides insight into each stage of this process: digitising a hard copy clinical decision support tool, training nurses without prior eHealth experience and implementing the tool in everyday clinical practice in four primary care clinics in the Western Cape province of South Africa. Lessons learnt throughout these experiences and future

\section{Summary box}

- Primary Care 101 (PC101), now called PACK (Practical Approach to Care Kit), is an effective pointof-care clinical decision support tool for primary care in health systems in low-income and middle-income countries.

- Digital delivery of medical content has potential benefits for healthcare workers, patients and health systems.

- The development and implementation of electronic PC101 across four primary care clinics in South Africa has demonstrated its feasibility and has flagged challenges for its further development and scaling.

steps for its development, evaluation and implementation will be described.

\section{THE PRACTICAL APPROACH TO CARE KIT PROGRAMME}

The PACK (Practical Approach to Care Kit) programme is a comprehensive health systems intervention designed for LMICs that comprises four 'pillars': a clinical decision support tool called the PACK guide,$^{3}$ an implementation strategy, ${ }^{4}$ and health systems strengthening and monitoring and evaluation components.

Developed by the KTU, this programme has undergone four generations of expansion, evaluation and improvement: Practical Approach to Lung Health in South Africa (PALSA), PALSA Plus, Primary Care 101 (PC101) and PACK. ${ }^{5-8}$ Beginning with the management of tuberculosis and respiratory care in the PALSA guide, PC101 and the PACK guides now include comprehensive coverage of all important primary care conditions in adults. PC101 (later renamed by the South African Department of Health to be Adult 
Primary Care) forms a central clinical component of the South African National Department of Health's primary care improvement initiative and policies. ${ }^{9}$ Usage of the programme as PACK has also spread beyond South Africa's borders to other LMICs including Botswana, Brazil, Nigeria and Ethiopia. ${ }^{10-13}$

The PACK guide and its predecessors are designed for nurse-led primary care clinics but provide for use for all front-line primary care clinicians, including doctors. Based on algorithms and structured lists, the PACK guide is a 120-page document, printed in full colour on highquality paper and is spiral-bound. The current version of PACK addresses 40 or more common presenting symptoms and more than 20 chronic conditions in adults. These include infectious diseases, chronic diseases of lifestyle, chronic respiratory diseases, mental health, reproductive health, musculoskeletal conditions, epilepsy and palliative care. ${ }^{3}$ It contains over 2300 diagnostic, screening and management recommendations based on current best evidence and relevant guidelines. Four pragmatic randomised control trials evaluating the guides confirmed substantial improvements over non-guideline-based care (PALSA) and then modest but consistent benefits on several process and health outcomes (PALSA Plus, PC101). ${ }^{5-8}$

\section{ADDRESSING DEMAND FOR A DIGITAL CLINICAL DECISION SUPPORT TOOL}

While the potential advantages of digitisation have been clear since the inception of the PACK programme, several factors catalysed the decision to pilot an electronic version. Technological advances contributed to an increased availability of user-friendly hardware and software, reduced prices for tablets, and therefore improved feasibility for an electronic clinical decision support tool in underserved health systems. In addition, the political environment has recently been receptive to technological innovation. The South African Department of Health has outlined its national strategy for developing eHealth and lists 10 strategic eHealth priorities-one of which is the "Applications and Tools to support healthcare delivery'. ${ }^{14}$

There were several aspects of the printed PC101 guide that had been identified as limitations. In the Western Cape, where the PC101 programme was developed and initially evaluated, evolving local policy necessitated annual updates of the guide. Printing the guides and coordinating their delivery every year are costly and time-consuming. Once printed, the content was soon out of date. Having an electronic version would allow for the implementation and dissemination of crucial updates before its annual revision. In addition, users of the printed guide required practice to navigate it quickly during a clinical consultation, and an interactive, electronic version offered the potential to improve user experience.

\begin{tabular}{|c|c|c|}
\hline & $\begin{array}{l}\text { Version } 1 \text { (e- } \\
\text { PC101) }\end{array}$ & Version 2 (e-PACK) \\
\hline Purpose & $\begin{array}{l}\text { To test user } \\
\text { acceptability. }\end{array}$ & $\begin{array}{l}\text { To produce a functional } \\
\text { version for uptake at scale. }\end{array}$ \\
\hline Based on & PC101 guide. & PACK guide. \\
\hline \multirow[t]{2}{*}{ Features } & $\begin{array}{l}\text { Basic version with } \\
\text { core functionality } \\
\text { designed to } \\
\text { balance cost with } \\
\text { output. }\end{array}$ & $\begin{array}{l}\text { Programmed application } \\
\text { that can be remotely } \\
\text { updated regularly. }\end{array}$ \\
\hline & $\begin{array}{l}\text { Optimised for } \\
\text { tablet viewing. }\end{array}$ & $\begin{array}{l}\text { Fully optimised across } \\
\text { multiple digital platforms. }\end{array}$ \\
\hline Format & Adobe PDF. & $\begin{array}{l}\text { Native application using } \\
\text { HTML5. }\end{array}$ \\
\hline $\begin{array}{l}\text { Developed } \\
\text { by }\end{array}$ & $\begin{array}{l}\text { Inhouse KTU } \\
\text { information } \\
\text { technology } \\
\text { manager and } \\
\text { graphic designer. }\end{array}$ & $\begin{array}{l}\text { Outsourced to specialist } \\
\text { to develop tailored content } \\
\text { platform. }\end{array}$ \\
\hline
\end{tabular}

KTU, Knowledge Translation Unit; PACK, Practical Approach to Care Kit; PC101, Primary Care 101; e-PACK, electronic PACK; ePC101, electronic PC101.

\section{DEVELOPING THE TOOL}

In January 2012, the KTU partnered with the Medical Device Innovation Platform of the South African Medical Research Council to develop a tablet adaptation of PC101. The PC101 guide was used as it was the version of the guide in use at the time. A design thinking approach was adopted in order to ensure that the tool was optimised for user needs. Prototyping, a key component of the design thinking process, was essential for gauging user feedback, exposing unanticipated challenges and evaluating project feasibility. ${ }^{15}$ The tool's development was separated into two iterations: version 1 (electronic PC101 [e-PC101]) and version 2 (electronic PACK [e-PACK]). Version 1 (e-PC101), the focus of this paper, is an adaptation of the PC101 guide. Version 2 (e-PACK), which is currently in development, is an adaptation of the paper version of the PACK guide. It will incorporate the feedback elicited from the development and piloting of e-PC101, and will be evaluated in Nigeria and Brazil. ${ }^{11} 12$

Partitioning the tool's development into two iterations allowed for its agile development, ensuring that user feedback collected from the implementation of version 1 could be incorporated into the design of version $2 .{ }^{16}$ Keeping objectives modest for the development of version 1 allowed for the collection of valuable feedback without the costs required to build a fully operating electronic clinical decision support tool. A comparison of versions 1 and 2 is provided in table 1 .

A team of clinician guideline developers, graphic artists, information technology specialists and project management administrators identified a series of objectives to guide the development of e-PC101. Objectives included determining appropriate software development vendors, 
Table 2 Development objectives and outputs of e-PC101 version 1

\begin{tabular}{|c|c|}
\hline Objective & Output \\
\hline $\begin{array}{l}\text { Efficient, } \\
\text { accessible, } \\
\text { practical use } \\
\text { in clinical } \\
\text { settings }\end{array}$ & $\begin{array}{l}\text { Multiple ( } \mathrm{n}=8 \text { ) software companies were interviewed and different software technologies (Windows, iOS, } \\
\text { Android, ePUB) were explored. } \\
\text { ePUB technology was dismissed because it was not able to display a full A4 landscape guideline page. The } \\
\text { content for this guideline could not reflow and had to retain its algorithmic structure. } \\
\text { HTML5 was potentially suitable due to its cross-platform capability and offline storage of web content, which } \\
\text { would have been a significant advantage for clinics with limited internet connectivity. It was rejected because } \\
\text { it could only display complex algorithms as static images, within which it would not be possible to search for } \\
\text { text. } \\
\text { A native application for an Android platform would allow for the content of the guideline to be extracted } \\
\text { and stored in a content management system, separating content from presentation and allowing for version } \\
\text { control, digital rights management, security and encryption. This was dismissed because it would require } \\
\text { costly and sophisticated software development, which was premature given the lack of user testing and } \\
\text { feedback to inform specifications. } \\
\text { Adobe InDesign was selected because of its ability to export in PDF with hyperlinks, the accessibility of PDF } \\
\text { readers on mobile platforms and the KTU's familiarity with the program. }\end{array}$ \\
\hline $\begin{array}{l}\text { nlining } \\
\text { ation } \\
\text { ut } \\
\text { cing } \\
\text { onality } \\
\text { sign }\end{array}$ & $\begin{array}{l}\text { The Adobe InDesign print version of the guideline was converted to a digital format through the following } \\
\text { processes: } \\
\text { Layout was optimised for the screen in consultation with the graphic artist responsible for the print version. } \\
\text { This involved repositioning tabs, converting algorithms that spanned multiple pages into single, scrollable } \\
\text { versions, and adjusting algorithm ratios to better fit screen sizes. } \\
\text { Hyperlinks and cross-references were used for skipping to certain page numbers. } \\
\text { Snapplify e-Reader technology was selected for encryption, security of the document and user } \\
\text { authentication, as it is supported on both Android and iOS platforms. } \\
\text { Tablets were selected to optimise display of the A4 landscape guide pages. The KTU has devoted considerable } \\
\text { effort over many years into ensuring a 'one-construct-per-page' display of content in the paper version. } \\
\text { This feature was retained as it allows users to attend to each section of the algorithm as new information is } \\
\text { processed while retaining awareness of their progress towards clinical decision-making. This is a departure from } \\
\text { the typical way in which algorithms have previously been digitised, displaying only one node at a time, often } \\
\text { assuming binary responses and uncoupling the user from an overview of the complete clinical decision-making } \\
\text { process. }\end{array}$ \\
\hline
\end{tabular}

KTU, Knowledge Translation Unit; PC101, Primary Care 101; e-PC101, electronic PC101.

identifying best practices in digitisation and piloting the tool to gather feedback (table 2).

A challenge that the KTU encountered while producing e-PC101 was the knowledge gap between the KTU staff and commercial software developers. Selecting a vendor to develop e-PC101 required a nuanced understanding of the relative advantages and disadvantages of coding languages, frameworks and content delivery platforms. This experience highlights the importance of bridging the fields of guide development and electronic content delivery by involving interdisciplinary advisors in the creation of eHealth applications. ${ }^{17}$

\section{TRAINING NURSES TO USE A DIGITAL CLINICAL DECISION SUPPORT TOOL}

Seventeen nurses were trained to use e-PC101 during two 1-day workshops, with no distance education or follow-up training. A designated staff trainer employed by the KTU facilitated training at the nurses' place of work. The case-based training revolved around applying e-PC101 to index cases-hypothetical scenarios that reflect common clinical encounters. This represents a significant departure from the traditional model of training for primary care health workers, where didactic training is provided off-site and out of context with little attempt to integrate with the clinical setting.

The tablet contained no applications other than e-PC101. Each nurse was provided with a bag for transporting the tablet within the clinic and to and from home. The training programme focused on establishing competency in several domains, including navigation of the device, usability during practice, safety and security, and integration in the health facility.

Throughout the training process, several insights became apparent. While all nurses owned cellphones, few used the technology to assist during clinical consultations. This can be attributed to a number of factors, including nurses' ownership of standard cellphones rather than smartphones, unstable wireless connection in rural clinics and a lack of confidence in using mobile technology.

Initial training in the use of e-PC101 appears to provide an adequate introduction to the digital tool despite a general prior lack of mastery of mobile technology. All users reported that they were successfully able to use the digital version, and none felt overwhelmed or stressed at the prospect of incorporating the tool in the clinic. Nurses felt that e-PC101 was a practical tool that could feasibly become integrated in their workflow. However, nurses noted that since 
e-PC101 would enforce a more detailed, time-consuming examination of patients, this would lead to the challenge of balancing comprehensive clinical assessments with heavy clinic demands. In addition, nurses expressed concern about the amount of time and resources necessary to train all healthcare workers to use e-PC101 and that a general lack of self confidence in technological competency might be an obstacle to scaling up.

\section{IMPLEMENTING A DIGITAL GUIDE}

The initial implementation of e-PC101 was conducted over a 2-month period in 2014 across four clinics in the Eden District of South Africa. e-PC101 was loaded onto 10 Samsung GT-P5200 32-gigabyte tablets for use by nurses.

Permission was obtained from the Provincial Government of the Western Cape (Department of Health), and all nurses were provided with comprehensive written information about the purpose of the study. Methodology for data collection is provided in online supplementary file 1 .

After the 2-month pilot period, discussions with nurses were held to solicit feedback and gauge the feasibility of scaling e-PC101. Nurses' reflections on the effectiveness and feasibility of e-PC101 were overwhelmingly positive. The nurses reported using e-PC101 extensively during consultations. Most nurses found that the digitised version was more effective and that they were able to read the material easily on the tablet. There was consensus among nurses that e-PC101 would benefit their practice. One group of nurses grew so attached to the intervention that they expressed reluctance to return the tablet after the pilot ended and even offered to purchase their own devices. Nurses emphasised how critical e-PC101 was to their clinical workflow by suggesting that their employer should obtain the digital tool even before official distribution was formalised. When comparing the e-version with the printed guide, all but one nurse indicated that they found e-PC101 faster, more intuitive and ultimately more helpful. Some nurses described a short adjustment period during which additional time was necessary to learn to use the platform. Besides their impression of quicker consultations and more tool-adherent care, e-PC101 improved their confidence. Using tablet technology made nurses feel professional, self-confident and knowledgeable. Nurses also noted that patients were intrigued by the new device, asking about its purpose and showing excitement about the use of new technology in their care. This mirrors experiences in which the introduction of novel health information technology has increased health workers' confidence and satisfaction. ${ }^{1819}$

In terms of functionality, nurses reported that they often searched within a page for certain words, zoomed to enlarge the text, used the 'return' button, swiped to turn pages, and made use of both the calendar and calculator applications. Features that were seldom used included highlighting and annotation. Participants indicated that highlighting and note-taking functions might be used more frequently once they had their own permanent tablet with e-PC101. The overall user interface was received as intuitive and time-saving. The battery was able to last throughout each working day, requiring only overnight charging. A significant limitation noted was that unstable wireless connectivity could limit regular updating of content. Nurses did not find the evidence updating processes as advantageous as expected. Instead, the rapid navigation of content during clinical consultations was the greatest perceived benefit.

Nurse feedback emphasised the need for improved security of the device from theft. Nurses across all clinics expressed concern about the safety of using expensive mobile technology in clinical settings. Many nurses explained that they hid the tablet under sheets of paper as a precautionary measure. One nurse said that "The fear of stealing it from the room was horrible," while another said that she initially refused to take the tablet out of the room, but eventually, "the anxiety disappeared." Several participants suggested security features for the tablet, including a locked box that could house the tablet, or mounting the tablet permanently on the clinic wall. Other suggestions included adding features for printing, flagging newly updated content, expanding content to include paediatric populations, and adding more multimedia content such as video.

\section{THE WAY FORWARD FOR ELECTRONIC PRIMARY CARE 101}

The findings of our limited pilot of e-PC101 support the hypothesis that digitising the PACK guides could help facilitate practical, streamlined, evidence-based healthcare.

Consultations have been initiated with the South African national and provincial departments of health as well as the private health sector regarding further implementation of e-PC101. Health workers and managers in the Western Cape have expressed interest in obtaining an electronic version of the guide to expedite distribution of the annual revision.

PACK is currently in high global demand, with many countries expressing interest in adopting the programme for their primary care services. ${ }^{20}$ To facilitate dissemination and implementation, a partnership has been established with the BMJ Publishing Group to develop and test tools to help spread PACK cost-effectively. For example, a linkage with BMJ Best Practice permits ready access to current guideline recommendations to inform the annual process of updating PACK guides. PACK in an electronic format in different LMICs could be easily updated, without the cost and delays involved in printing revised versions.

Because the demand to rapidly introduce novel eHealth interventions is often steered by political economic pressures and an appetite for innovation, there has been a documented absence of rigorous validation prior to widespread implementation. ${ }^{21}{ }^{22}$ Further formal evaluation is needed to assess the effectiveness of e-PC101 over the hard copy version. In addition to measuring the quantitative impact of the tool, its features and outcomes should 
also be compared with other clinical decision support tools designed for LMICs. ${ }^{23} 24$

\section{CONCLUSION}

The KTU believes that digital guides like e-PC101 have the potential to improve quality of care in under-resourced health systems by systematising the comprehensiveness and thoroughness of the clinical examination and history, and by streamlining the process whereby new evidence is available for front-line clinicians. The introduction of a complex eHealth intervention in an LMIC has distilled several challenges and opportunities regarding design priorities, effective training and security protocols. Feedback for improved features provided by front-line nurses has been considered and incorporated into a second iteration. Front-line nurses with no previous experience with digital health tools felt that the 2-day workshop was sufficient training for practical use of the tool.

The lessons learnt throughout this process will inform the continued development and evaluation of this LMIC clinical decision support tool.

Acknowledgements Dr Anthony Bunn of the SA MRC as funding lead, Dr Beverly Draper (project manager), Dr Catherine Draper (protocol development), Gill Faris (training programme design) Dr Giovanni Milandri (for advice on application development), Kerry Abramowitz (for graphic design), Dr Renette Crous, the District Manager and nurses from the four clinics who participated in the pilot.

Contributors MY performed the analysis of results and drafted the paper. VT contributed to the development of the device. PM and VT performed the field testing. MZ, LF, RVC and EDB were involved in the concept and design of the evaluation and the analysis of results. All authors contributed substantially to the drafting and revision of the manuscript and approved the final version.

Funding Financial support for this project was received from Medical Device Innovation Platform of the South African Medical Research Council and from the University of Cape Town Lung Institute.

Competing interests MY and MZ declare no competing interests. LF and RVC are employees of the University of Cape Town Lung Institute. VT is an ex-employee of the University of Cape Town Lung Institute. PM was an employee of the University of Cape Town. EDB is a part-time employee of the University of Cape Town Lung Institute, and reports personal fees from ICON, Novartis, Cipla, Vectura, Menarini, ALK, Sanofi Regeneron, Boehringer Ingelheim and AstraZeneca, and grants to his institution for clinical trials from Novartis, Boehringer Ingelheim, Merck, Takeda, GlaxoSmithKline, Hoffmann-La Roche, Actelion, Chiesi, Sanofi-Aventis, Cephalon, TEVA and AstraZeneca. All EDB's fees and clinical trials are for work outside the submitted work. EDB is a member of the Global Initiative for Asthma Board and Science Committee. Since August 2015 the KTU and BMJ have been engaged in a non-profit strategic partnership to provide continuous evidence updates for PACK, expand PACK-related supported services to countries and organisations as requested, and where appropriate licence PACK content. The KTU and BMJ cofund core positions, including a PACK Global Development Director, and receive no profits from the partnership. PACK receives no funding from the pharmaceutical industry. This paper forms part of a Collection on PACK sponsored by the BMJ to profile the contribution of PACK across several countries towards the realisation of comprehensive primary healthcare as envisaged in the Declaration of Alma Ata, during its 40th anniversary.

Patient consent for publication Not required.

Provenance and peer review Not commissioned; externally peer reviewed.

Data sharing statement № additional data are available.

Open access This is an open access article distributed in accordance with the Creative Commons Attribution Non Commercial (CC BY-NC 4.0) license, which permits others to distribute, remix, adapt, build upon this work non-commercially, and license their derivative works on different terms, provided the original work is properly cited, appropriate credit is given, any changes made indicated, and the use is non-commercial. See: http://creativecommons.org/licenses/by-nc/4.0

\section{REFERENCES}

1. Lewis T, Synowiec C, Lagomarsino G, et al. E-health in low- and middle-income countries: findings from the center for health market innovations. Bull World Health Organ 2012;90:332-40.

2. Blaya JA, Fraser HSF, Holt B. E-health technologies show promise in developing countries. Health Aff 2010;29:244-51.

3. Cornick R, Picken S, Wattrus C, et al. The practical approach to care kit (pack) guide: developing a clinical decision support tool to simplify, standardise and strengthen primary healthcare delivery. BMJ Glob Health 2018;3(Suppl 5):e000962.

4. Simelane ML, Georgeu-Pepper D, Ras CJ, et al. The practical approach to care kit (pack) training Programme: scaling up and sustaining support for health workers to improve primary care. BMJ Glob Health 2018;3(Suppl 5):e001124.

5. Fairall LR, Zwarenstein M, Bateman ED, et al. Effect of educational outreach to nurses on tuberculosis case detection and primary care of respiratory illness: pragmatic cluster randomised controlled trial. BMJ 2005;331:750-4

6. Zwarenstein M, Fairall LR, Lombard C, et al. Outreach education for integration of HIV/AIDS care, antiretroviral treatment, and tuberculosis care in primary care clinics in South Africa: PALSA plus pragmatic cluster randomised trial. BMJ 2011;342:d2022.

7. Fairall LR, Folb N, Timmerman V, et al. Educational outreach with an integrated clinical tool for nurse-led non-communicable chronic disease management in primary care in South Africa: a pragmatic cluster randomised controlled trial. PLoS Med 2016;13:e1002178.

8. Fairall L, Bateman E, Cornick R, et al. Innovating to improve primary care in less developed countries: towards a global model. BMJ Innov 2015;1:196-203.

9. National Department of Health. Adult primary Care (APC) guide. Available: https://www.knowledgehub.org.za/content/adult-primarycare-apc-guide

10. Tsima BM, Setlhare V, Nkomazana O. Developing the Botswana primary care guideline: an integrated, symptom-based primary care guideline for the adult patient in a resource-limited setting. $J$ Multidiscip Healthc 2016;9:347-54.

11. Awotiwon A, Sword C, Eastman T, et al. Using a mentorship mode to localise the practical approach to care kit (pack): from South Africa to Nigeria. BMJ Glob Health 2018;3(Suppl 5):e001079.

12. Wattrus $\mathrm{C}$, Zepeda J, Cornick RV, et al. Using a mentorship model to localise the practical approach to care kit (pack): from South Africa to Brazil. BMJ Glob Health 2018;3(Suppl 5):e001016.

13. Cornick R, Wattrus $C$, Eastman $T$, et al. Crossing borders: the pack experience of spreading a complex health system intervention across low-income and middle-income countries. BMJ Glob Health 2018;3(Suppl 5):e001088.

14. Republic of South Africa Department of Health. eHealth strategy South Africa, 2012

15. Brown T, Wyatt J. Design thinking for social innovation. Development Outreach 2010;12:29-43.

16. Williams L, Cockburn A. Guest editors' introduction: Agile software development: it's about feedback and change. Computer 2003;36:39-43.

17. Pagliari C. Design and evaluation in eHealth: challenges and implications for an interdisciplinary field. J Med Internet Res 2007;9.

18. Chae YM, Kim SI, Lee BH, et al. Implementing health management information systems: measuring success in Korea's health centers. Int J Health Plann Manage 1994;9:341-8.

19. Singh AK, Kohli M, Trell E, et al. Bhorugram (India): revisited. A 4 year follow-up of a computer-based information system for distributed MCH services. Int J Med Inform 1997;44:117-25.

20. Fairall L, Cornick R, Bateman E. Empowering frontline providers to deliver universal primary healthcare using the practical approach to care kit. BMJ 2018;363.

21. Ruwaard J, Kok R. Wild West eHealth: time to hold our horses? Health Psychol Rev 2015;17:45-9.

22. Baker TB, Gustafson DH, Shah D. How can research keep up with eHealth? ten strategies for increasing the timeliness and usefulness of eHealth research. J Med Internet Res 2014;16.

23. Clifford GD. E-health in low to middle income countries. J Med Eng Technol 2016;40:336-41.

24. Ali MK, Shah S, Tandon N. Review of electronic decision-support tools for diabetes care: a viable option for low- and middle-income countries? J Diabetes Sci Technol 2011;5:553-70. 